\title{
Performance Comparison between the ORIGINAL FORMS OF BIOGEOGRAPHY-BASED OPTIMIZATION ALGORITHMS
}

\author{
Ali R. Alroomi ${ }^{1}$, Fadhel A. Albasri ${ }^{2}$ and Jawad H. Talaq ${ }^{3}$ \\ ${ }^{1}$ Electrical Engineer, University of Bahrain, Sakhir, Bahrain \\ wadyan@gmail.com \\ ${ }^{2}$ Department of Electrical Engineering, University of Bahrain, Sakhir, Bahrain \\ falbasriauob.edu.bh \\ ${ }^{3}$ Department of Electrical Engineering, University of Bahrain, Sakhir, Bahrain \\ jhstallaqdeng.uob.bh
}

\begin{abstract}
Biogeography-based optimization (BBO) is a new population-based evolutionary algorithm and one of meta-heuristic algorithms. This technique is based on an old mathematical study that explains the geographical distribution of biological organisms. The first original form of $B B O$ was introduced in 2008 and known as a partial migration based BBO. Few months later, BBO was re-introduced again with additional three other forms and known as single, simplified partial, and simplified single migration based BBOs. Then a lot of modifications were employed to enhance the performance of $B B O$. However, the literature lacks the explanations and the reasons on which the modifications are based on. This paper tries to clarify this issue by making a comparison between the four original BBO algorithms through a variety of benchmark functions with different dimensions and complexities. The results show that both single and simplified single migration based BBOs are faster, but have less performance as compared to the others. The comparison between the partial and the simplified partial migration based BBOs shows that the preference depends on the population size, problem's complexity and dimensions and the values of the upper and lower side constraints. The partial migration model wins when these factors, except population size, are increased, and vice versa for the simplified partial migration model. The results can be used as a foundation and a first step of modification for enhancing any proposed modification on $B B O$ including the existing modifications that are described in literature.
\end{abstract}

\section{KEYWORDS}

Biogeography-Based Optimization, BBO, Simplified BBO, Evolutionary Algorithm, Partial Migration, Single Migration

\section{INTRODUCTION}

The science ofbiology becomes one of the main resources of inspiration to develop the modern optimization techniques, such as ant colony optimization (ACO), bee colony optimization (BCO), wasp swarm optimization (WSO), bacterial foraging optimization (BFO), genetic algorithm (GA), evolutionary strategy (ES), differential evolution (DE), particle swarm optimization (PSO), etc. Biogeography-based optimization (BBO) is a new population-based evolutionary algorithm (EA)

Sundarapandian et al. (Eds) : ICAITA, SAI, SEAS, CDKP, CMCA-2013

pp. 121-140, 2013. (C) CS \& IT-CSCP 2013

DOI : 10.5121/csit.2013.3811 
that was introduced by Dan Simon in 2008 [1], and its performance was evaluated based on 14 benchmark functions, and then was tested to solve a real sensor selection problem for aircraft engine health estimation. BBO did well and proved that it is a very competitive method as compared to the other EAs. Since then, a lot of researches have been conducted, some of them to solve practical problems such as economic emission load dispatch [20], land cover feature extraction [21], and unit commitment [22]; while the others were focused to enhance and modify its performance $[23,24,25,26,27,29,33]$.

The objective of this paper is to outline a clear path for selecting the best algorithm among the four original forms, and thus, any present modification with wrong selected form can be reviewed again with this guidance to enhance its performance. In addition, it can be used as a foundation for any future modification.

This paper is organized as follows: Section II gives a quick introduction about the theory of island biogeography to be as a strong basis to understand the principles of the original BBOs which are described in Section III; after that, Section IV gives a comparison between the original forms of BBO. Section V is set for the conclusions.

\section{THE THEORY OF ISLAND BIOGEOGRAPHY}

Biogeography is a branch of biology, and it is a synthetic discipline, relying heavily on theory and data from ecology, population biology, systematics, evolutionary biology, and the earth sciences [4]. Biogeography seeks to describe, analyze and explain the geographic patterns and changing distributions of ecosystems and fossil species of plants (flora) and animals (fauna) through geological space and time [5, 6].

Island, in biogeography, is any area of suitable habitat (local environment occupied by an organism [7]) surrounded by an expense of unsuitable habitat and is endowed with exceptionally rich reservoirs of endemic, exclusive, strange and relict species [8]. Islands as ecological systems have such salient features as simple biotas, varying combinations of biotic and abiotic factors, and variability in isolation, shape, and size $[9,14]$. With these characteristics, islands represent themselves as natural experiments, and got highly attentions by the nineteenth century naturalists of the first rank, such as Alfred R. Wallace in East Indies [10], Charles Darwin in Galapagos Islands [11] and Joseph D. Hooker in Southern Ocean [12].

Island biogeography is a special field within biogeography science. This field was initially started by the ecologists Robert H. MacArthur and Edward O. Wilson in 1960 to 1963 with their published paper [2], and continued their studies till 1967 when the final achievement were presented in [3]; and recently, this theory has been revisited and expanded more in [13].

Island biogeography theory fully integrates much of ecology, population biology, evolution, and paleontology, with important implications for conservation of species [13]. It was developed with mathematical models for attempting to translate the ecology and biogeography from the traditional view to analytical view, and answering why some islands are rich of species while the others are poor, by establishing and explaining the biotic (like predation, competition and interactions between species) and abiotic (like wind, water, sunlight, temperature, pressure and soil) factors that affect the species richness of natural communities in an island [15]. Thus, it gives the ability to predict the species counts that migrate between islands and then can find the optimum conservation areas $[4,5,6,8]$. 
The equilibrium theory of island biogeography proposes that the number of inhabited species on an island is based on the dynamic equilibrium between new immigrated species onto an island and the extinct species out from that island $[2,3,13]$.

Fig. 1 graphically represents the equilibrium model with exponential immigration (or speciation) rate $\lambda$ and emigration (or extinction) rate $\mu$, where they can also be plotted as a logistic, linear or any proper function $[4,16,17]$, while the equilibrium location will be shifted to the right or left based on the type of rate functions, the island's area and/or the distance (isolation) between the source and recipient islands $[4,3,13]$.

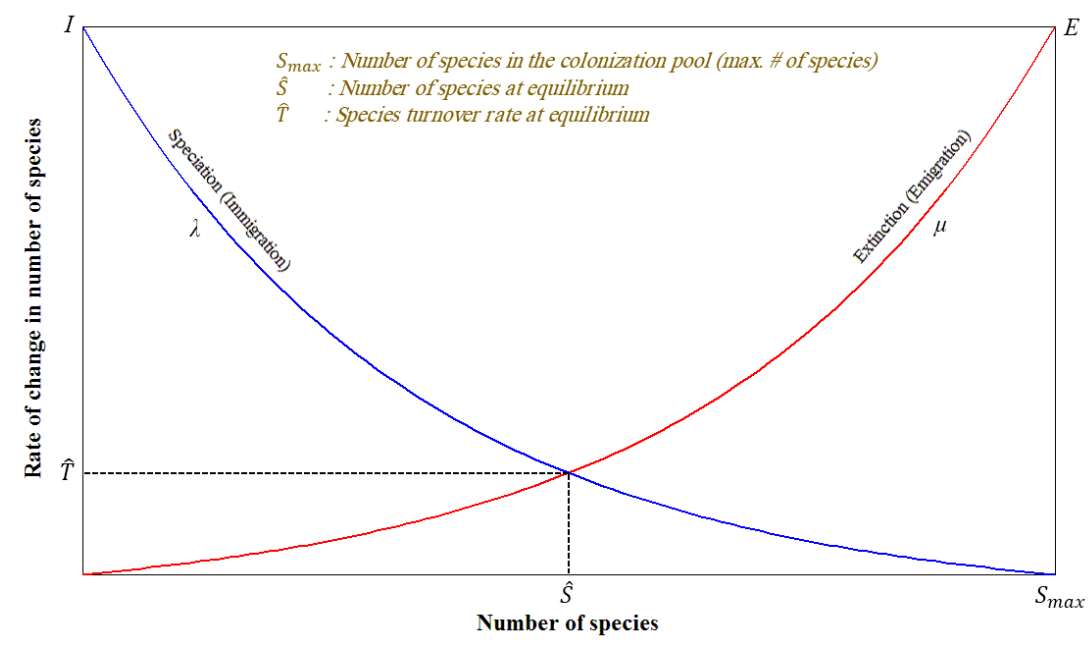

Figure 1. Equilibrium model of a biota of a single island

$I$ and $E$ are the maximum possible immigration and emigration rates, respectively. $\hat{S}$ is the number of species at equilibrium, $\widehat{T}$ is the species turnover rate at equilibrium, and $S_{\max }$ is the maximum number of species on that island.

$I$ occurs when there is no colonization process, or in other word, the island is empty of any species and it will offer maximum opportunity to the species on the other islands for immigrating to settle on it; and as the number of arrived species on that island increases, the opportunity for settlement will decrease and thus the immigration rate will decrease too. Also, as $\lambda$ decreases, the species density increases, so the predation, competition and parasitism factors will increase; and as a result, the emigration rate $\mu$ will increase, and reaches its maximum value $E$ when $\lambda$ reaches its minimum value [18].

MacArthur and Wilson [2,3] simplified theexponential model to be as a linear function, where $I=E$ as shown in Fig. 2 with mathematical expressions in order to theoretically explain how the migration process on a single island happens.

Now, let at time $t$, the recipient island has $S$ species with probability $P_{S}(t)$, and $\lambda_{s}$ and $\mu_{s}$ are respectively the immigration and emigration rates at the present of $S$ species on that island. Then the variation from $P_{S}(t)$ to $P_{S}(t+\Delta t)$ can be described as:

$$
P_{s}(t+\Delta t)=P_{s}(t)\left(1-\lambda_{s} \Delta t-\mu_{s} \Delta t\right)+P_{s-1}(t) \lambda_{s-1} \Delta t+P_{s+1}(t) \mu_{s+1} \Delta t
$$

Also, $\hat{S}$ can be found by using different methods. From the basic of trigonometry: 


$$
\begin{gathered}
\frac{\hat{T}}{\hat{S}}=\frac{E}{S_{\max }} \Rightarrow \hat{T}=\frac{E}{S_{\max }} \hat{S} \\
\frac{\hat{T}}{\left(S_{\max }-\hat{S}\right)}=\frac{I}{S_{\max }}
\end{gathered}
$$

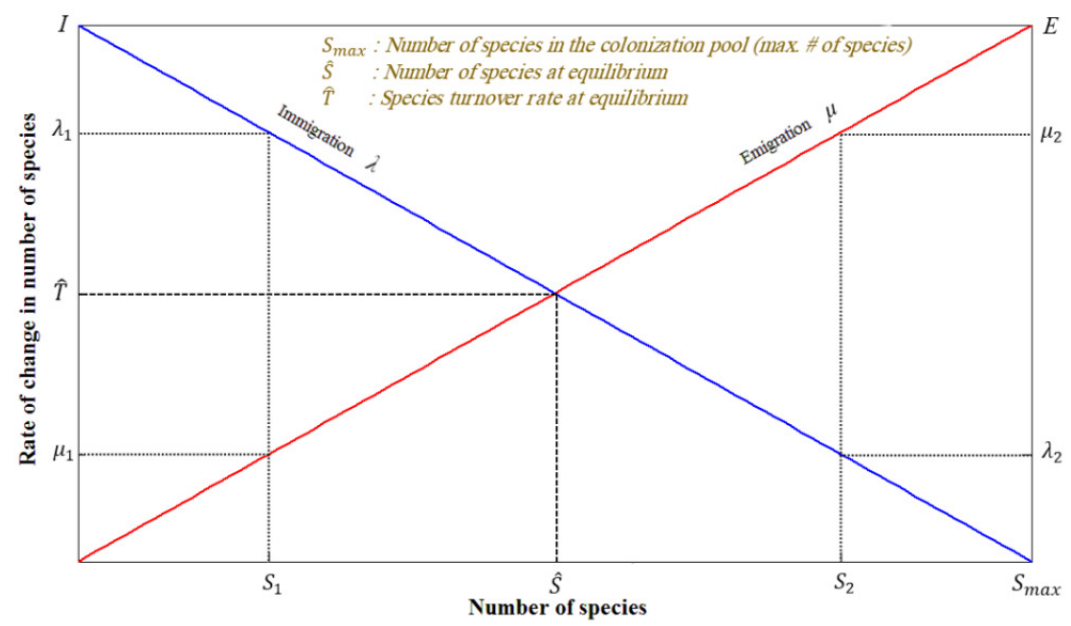

Figure 2. Simplified equilibrium model of a biota of a single island

Substituting Eq. 2 in Eq. 3 for $\widehat{T}$ :

$$
\hat{S}=\left(\frac{I}{I+E}\right) S_{\max }
$$

Eq. 4 can also be obtained by equalizing $\lambda_{s}$ and $\mu_{s}$ rates at $\widehat{S}$ as follows:

$$
\begin{gathered}
\mu_{s}=\frac{E}{S_{\max }} S \\
\lambda_{s}=1-\mu_{s}=I\left(1-\frac{S}{S_{\max }}\right) \\
\text { at } S=\hat{S}: \quad \lambda_{s}=\mu_{s} \Rightarrow I\left(1-\frac{\hat{S}}{S_{\max }}\right)=\frac{E}{S_{\max }} \hat{S}
\end{gathered}
$$

Solving Eq. 7 for $\hat{S}$ gives Eq. 4; where at the intersection point, the island's biota will be at a state of dynamic equilibrium, and thus $P_{s}(t+\Delta t)=P_{\max }[1,3,17]$.

From Eq. 1, to have $S$ at time $(t+\Delta t)$, one of the following three conditions should hold:

1. $S$ species at time $t$, and no immigration or emigration took place during the interval $\Delta t$;

2. $(S-1)$ species at time $t$, and one species immigrated;

3. $(S+1)$ species at time $t$, and one species emigrated.

To neglect the probability of more than one immigration or emigration, then $\Delta t$ has to be set with small value. As $\Delta t$ approaches 0 , the ratio $\left(\frac{\Delta P_{s}}{\Delta t}\right)$ approaches $\dot{P}_{s}(t)$ : 


$$
\begin{aligned}
& \frac{d P_{S}(t)}{d t} \cong \lim _{\Delta t \rightarrow 0} \frac{P_{S}(t+\Delta t)-P_{S}(t)}{\Delta t} \\
& \frac{d P_{S}(t)}{d t} \cong-\left(\lambda_{S}+\mu_{S}\right) P_{S}(t)+\lambda_{s-1} P_{S-1}(t)+\mu_{S+1} P_{S+1}(t)
\end{aligned}
$$

By considering the previous threeconditions, Eq. 8becomes:

$$
\dot{P}_{s}(t)=\left\{\begin{array}{cc}
-\left(\lambda_{s}+\mu_{s}\right) P_{s}+\mu_{s+1} P_{s+1}, & S=0 \\
-\left(\lambda_{s}+\mu_{s}\right) P_{s}+\lambda_{s-1} P_{s-1}+\mu_{s+1} P_{s+1}, & 1 \leq S \leq S_{\text {max }}-1 \\
-\left(\lambda_{s}+\mu_{s}\right) P_{s}+\lambda_{s-1} P_{s-1}, & S=S_{\max }
\end{array}\right.
$$

The value of $\dot{P}_{S}(t)$ can also be determined by using a matrix technique [1].

Thus, using the known values of $P_{S}(t)$ and $\dot{P}_{S}(t)$, the value of $P_{S}(t+\Delta t)$ given in Eq. 1 can be approximated as:

$$
P_{S}(t+\Delta t) \cong P_{S}(t)+\dot{P}_{S}(t) \Delta t
$$

Eq. 10 is the final form that has to be used in the program of $\mathrm{BBO}$ for calculating $P_{s}(t+\Delta t)$.

For finding $P_{S}(t)$, Dan Simon in [1] used two methods; either by solving Eq. 9 numerically, or by applying the following theorem:

Theorem 1: The steady-state value for the probability of the number of each species is given by:

$$
P(\infty)=\frac{v}{\sum_{i=1}^{s_{\max }+1} v_{i}}
$$

Where $v$ and $v_{i}$ are computed as:

$$
\begin{gathered}
v=\left[v_{1}, v_{2}, \ldots, v_{S_{\text {max }}+1}\right]^{T} \\
v_{i}=\frac{S_{\text {max }} !}{\left(S_{\text {max }}+1-i\right) !(i-1) !} \quad\left(i=1, \ldots, S_{\text {max }}+1\right)
\end{gathered}
$$

\section{BIOGEOGRAPHY-BASED OPTIMIZATION (BBO)}

The involvement of the science of biogeography into BBO is that the general problem solution means the natural distribution of species [1]. Each island represents one solution, where the good solution in biogeography means that the island has many species, and the density of these species depends on the availability of good features offered by that island (the good things of biotic "living: trees, shrubs, meadow, diversity of prey, etc" and abiotic "non-living: wind, temperature, humidity, water, area, etc" factors [19] - as described in section II), and vice versa for the poor solution islands [18]. Each feature is called suitability index variable (SIV), and represents the independent variable of such a problem in BBO [30].

Island suitability index (ISI) depends on the availability of those features on that island; and, in $\mathrm{BBO}, I S I$ is the dependent variable [30]. Thus, for problem with $n$-independent variables and $k$ islands or individuals, then it can be expressed as:

$$
I S I_{i}=f\left(S I V_{1}, S I V_{2}, \ldots, S I V_{n}\right) \quad i=1,2, \ldots, k
$$


The algorithm of $\mathrm{BBO}$ consists of two main sub-algorithms, migration and mutation.

The original forms of $\mathrm{BBO}$ depend on the type of the migration process, which are partial migration based (PMB-BBO), single migration based (SMB-BBO), simplified partial migration based (SPMB-BBO), and simplified single migration based (SSMB-BBO) $[1,28]$.

\subsection{Migration}

Considering Eq. 14, the high ISI for island irepresents a good solution, and also high ISI means large number of available species on that island, which forces immigration rate $\lambda_{s}$ to be low and emigration rate $\mu_{s}$ to be high; while low ISI for island $i$ represents a poor solution, which means a shortage indication in the availability of species on that island, where at this condition $\lambda_{s}$ is high and $\mu_{s}$ is low.

Referring to Fig. $2, S_{I}$ is located before $\hat{S}$, where $\lambda_{s}$ is high, $\mu_{s}$ is low and the solution $I S I_{I}$ is poor; while $S_{2}$ is located after $\widehat{S}$, where $\lambda_{s}$ is low, $\mu_{s}$ is high and the solution $I S I_{2}$ is good. Thus, $\lambda_{s}$ and $\mu_{s}$ are indications of poor and good solutions, respectively.

In migration process, the high ISI islands share their features to modify the low ISI islands, where the islands of both sides are probabilistically selected. The high ISI islands become the source of modification, while the low ISI islands become the recipients to those emigrated species.

Although the species will emigrate from the rich islands to the poor islands, this phenomena does not mean that the species will completely disappear from its home islands. However, only a few representatives emigrate [1]. Thus, the recipient islands are enhanced, and at the same time the source islands are kept away from any shortage on its richness of species.

The migration process of the four original forms of $\mathrm{BBO}$ can be described as:-

\subsubsection{PMB-BBO Model:}

Let $I S I_{i}$ denote the $i$ th population member and contains $n$ features

For each island $I S I_{i}$ (where $i=1,2,3, \ldots, k$ )

For each $S I V s$ (where $s=1,2,3, \ldots, n$ )

Use $\lambda_{i}$ to probabilistically select the immigrating island $I S I_{i}$

If rand $<\lambda_{i}$

For $j=1$ to $k$

Use $\mu_{j}$ to probabilistically decide whether to emigrate to $I S I_{i}$

If $I S I_{j}$ is selected

Randomly select an $S I V \sigma$ from $I S I_{j}$

Replace a random $S I V s$ in $I S I_{i}$ with $S I V \sigma$

end if

end for

end if

next $S I V$

next island 


\subsubsection{SMB-BBO Model:}

Let $I S I_{i}$ denote the $i$ th population member and contains $n$ features

For each island $I S I_{i}$ (where $i=1,2,3, \ldots, k$ )

Use $\lambda_{i}$ to probabilistically select the immigrating island $I S I_{i}$

If rand $<\lambda_{i}$

Pick a random $S I V s($ where $s=1,2,3, \ldots, n)$

For $j=1$ to $k$

Use $\mu_{j}$ to probabilistically decide whether to emigrate to $I S I_{i}$

If $I S I_{j}$ is selected

Randomly select an $S I V \sigma$ from $I S I_{j}$

Replace a random $S I V s$ in $I S I_{i}$ with $S I V \sigma$

end if

end for

end if

next island

The simplified models (SPMB and SSMB) are similar to the previous normal models (PMB and SMB), except that the simplified models will always use the best obtained solution as the emigrating island instead of doing an internal loop checking. It is apparent that the simplified models have two conflicting issues. They are faster (less CPU time) because the internal looping is eliminated. However, they could trap in a local minima because they always depend on the best solution, and consequently the probability of finding other better solutions reduces.

\subsubsection{SPMB-BBO Model:}

Let $I S I_{i}$ denote the $i$ th population member and contains $n$ features

For each island $I S I_{i}$ (where $i=1,2,3, \ldots, k$ )

For each $S I V s$ (where $s=1,2,3, \ldots, n$ )

Use $\lambda_{i}$ to probabilistically select the immigrating island $I S I_{i}$

If rand $<\lambda_{i}$

Select the best obtained solution as the emigrating island $I S I_{\text {best }}$

If $I S I_{\text {best }}$ is selected

Randomly select an $S I V \sigma$ from $I S I_{\text {best }}$

Replace a random $S I V s$ in $I S I_{i}$ with $S I V \sigma$

end if

end if

next $S I V$

next island 


\subsubsection{SSMB-BBO Model:}

Let $I S I_{i}$ denote the $i$ th population member and contains $n$ features

For each island $I S I_{i}$ (where $i=1,2,3, \ldots, k$ )

Use $\lambda_{i}$ to probabilistically select the immigrating island $I S I_{i}$

If rand $<\lambda_{i}$

Pick a random $S I V s($ where $s=1,2,3, \ldots, n)$

Select the best obtained solution as the emigrating island $I S I_{\text {best }}$

If $I S I_{\text {best }}$ is selected

Randomly select an $S I V \sigma$ from $I S I_{\text {best }}$

Replace a random $S I V s$ in $I S I_{i}$ with $S I V \sigma$

end if

end if

next island

\subsection{Mutation}

The features available on an island (i.e., $n-S I V$ ) can be changed dramatically due to random events called mutations [31], which forces $\hat{S}$ to deviate from its equilibrium value [1].

Most observed mutations are harmful, like predators from other islands, tsunamis, volcanos, diseases or earthquakes, which are not directed to be useful [17]. On the other hand, there are some useful events that can enhance those $n$-SIV to give better solutions, such as wind-carrying seeds (wind pollination) or flotsams (shipwreck) [18].

In $\mathrm{BBO}$, this mutation process is modeled as $S I V$ mutation, where the mutation rate $m$ can be determined by involving species count probabilities $P_{s}$ into the following equation:

$$
m=m_{\max }\left(1-\frac{P_{S}}{P_{\max }}\right)
$$

Where $P_{\max }=\max \left(P_{s}\right)$ and $m_{\max }$ is a user-defined maximum mutation rate that $m$ can reach. From Eq. 15, $m$ reaches to its minimum "zero" at the maximum value of $P_{s}$, and vice versa. Thus, $m$ is inversely proportional to $P_{s}$.

The objective of using mutation rate is to set the low and high ISI solutions likely to mutate, which gives them an ability to enhance their results more than what they already have, where the solutions at the equilibrium point are not mutated [1]. 
The mutation process can be described as:

For $i=1$ to $k$ (where $\mathrm{k}$ is the number of islands, see Eq. 14)

Calculate probability $P_{s}$ based on $\lambda_{s}$ and $\mu_{s}$ (by numerical or direct method)

Calculate mutation rate $m$ (using Eq. 15)

Select $I S I_{i}$ with probability proportional to $P_{s}$

If $I S I_{i}$ is selected

Replace $S I V$ of $I S I_{i}$ with a randomly generated $S I V$

end if

end for

\subsection{BBO Algorithm}

The steps of the general BBO algorithm can be listed as:

1. Initialize the BBO parameters $\left(S_{\max }, I, E, m_{\max }, e t c\right)$.

2. Find species count probabilities $P_{s}$ and mutation rate $m$ based on the calculated immigration rate $\lambda_{s}$ and emigration rate $\mu_{s}$ by Eqs. 5 and 6 .

3. Generate $k$ random islands, where each island represents one solution to a given problem with $n$-SIV.

4. Sort the solutions $k$-ISI for all islands, so the first best solution should be mapped with the highest number of species and the highest emigration rate $\mu_{s}$ (or the lowest immigration rate $\lambda_{s}$ ), and continue the descending order till reaching to the worst solution.

5. Do elitism process for saving the required best solutions for the next generation; it is an optional step [30].

6. Probabilistically select the source islands based on $\mu_{s}$, and the islands which need to be modified "the recipient islands" based on $\lambda_{s}$, and do the migration process. Then, update all $k$-ISI before ending this step.

7. Do mutation process for the islands based on their probabilities that are listed in the probability vector after calculated in step (2). Then, update all $k$-ISI once the mutation process is completed.

8. Return to step (4) for the next iteration. This loop can be terminated either if reaching to an acceptable tolerance or after completing the desired number of generations.

\section{Performance Comparison}

The main problem associated with all the modified BBOs is that the modifications were done on an arbitrary selected form of the four original forms. There is no clarification on which form the proposed modification stands on and why.

The four original forms of BBO have been tested through 23 benchmark functions with different dimensions and complexities.

These functions can be classified into three groups: unimodal, multimodal with few local minima and multimodal with many local minima. Functions f01-f13 are high-dimensional problems. 
Functions f01-05 and f07 are high-dimensional and unimodal, f06 is a high-dimensional step function with one discontinuous minimum. Functions f08-13 are high-dimensional and multimodal with many local minima, and the remaining functions are low-dimensional and multimodal with few local minima [33]. The details of these benchmark functions can be found in the Appendix.

The parameters that have been used here are similar to those used in $[25,29]$ : population size of $50, I=E=1, m_{\max }=0.01$, generation limit of 20,000 for f01-13 and 1000 for f14-23, elitism parameter of 1 , and Monte-Carlo simulation with 30 trails.

Table 1 summarizes the performance of PMB, SMB, SPMB and SSMB models for 23 benchmark functions. The highlighted cells in the tables represents the best result among the four BBO algorithms. It can be clearly seen that the performance of PMB and SPMB are superior as compared to SMB and SSMB. For high-dimensional problems, PMB wins with 7 best solutions, 10 mean and 8 standard deviation out of 13; while SPMB wins with 6 best solutions, 3 mean and 5 standard deviation. On the other hand, for low-dimensional problems, SSMB enters this competition, and gives better Best, Mean and Standard deviation than that of the PMB for the functions $\mathrm{f} 16$, f17,f18, but it does not win as compared to SPMB. Single and simplified single migration based models are not valid for f21-23, because these problems are 1-dimensional problems, and the migration process is done within only one independent variable.

Although, in overall, SSMB has respectively the first and second worst performance for high and low-dimensional problems, it achieved the fastest algorithm as shown in Table 2. This is logical, because of two reasons. First, it does a migration on one randomly selected $S I V$ for each island rather than all $n-S I V$ as in PMB and SPMB. Second, it will always select the best found solution as a source island for migration instead of doing a loop checking as in SMB. This is why the simplified versions of PMB and SMB trip in local minima particularly as the complexity, side constraints and/or dimensions increases and as the number of islands or population size decreases. In this situation, PMB has the best exploration and exploitation.

Table 1: Comparison of the results for 30 trails of the original four BBO models, where Best, Mean, and StdDev stands for the smallest error, the mean of all errors, and the standard deviation, respectively.

\begin{tabular}{|c|c|c|c|c|c|c|c|c|c|c|c|c|c|}
\hline \multirow{3}{*}{$f \#$} & \multirow{3}{*}{$\mathbf{n}$} & \multicolumn{12}{|c|}{ Biogeography Based Optimization (BBO) } \\
\hline & & \multicolumn{3}{|c|}{ Partial Migration Based } & \multicolumn{3}{|c|}{ Single Migration Based } & \multicolumn{3}{|c|}{ Simplified Partial Migration Based } & \multicolumn{3}{|c|}{ Simplified Single Migration Based } \\
\hline & & Best & & tdDev & Best & & StdDev & & & & & Mean & StdDev \\
\hline f01 & 30 & $1.8518 \mathrm{E}+00$ & $3843 E+00$ & $3964 \mathrm{E}+00$ & $.6999 \mathrm{E}+02$ & $1652 \mathrm{E}+02$ & $9742 E+01$ & $2.2588 \mathrm{E}+00$ & $4.3027 \mathrm{E}+00$ & $.3073 E+00$ & $8.1588 \mathrm{E}+01$ & $3.5592 \mathrm{E}+02$ & $.5209 \mathrm{E}+02$ \\
\hline f02 & 30 & 4.0024E-01 & 0184E-01 & & $3.8978 \mathrm{E}+00$ & $1515 \mathrm{E}+00$ & $.3348 \mathrm{E}+00$ & & $7.6268 \mathrm{E}-01$ & $1.0545 \mathrm{E}-01$ & $5.4535 \mathrm{E}+00$ & $7.3952 E+00$ & $.1782 \mathrm{E}+0 \mathrm{C}$ \\
\hline f03 & 30 & $433 \mathrm{E}+02$ & $9527 E+04$ & & $3679 E+03$ & $0638 \mathrm{E}+04$ & $3227 E+04$ & & $3.2307 \mathrm{E}+04$ & $.3231 \mathrm{E}+03$ & $4.4645 \mathrm{E}+02$ & $2.7268 \mathrm{E}+04$ & $4724 \mathrm{E}+0$ \\
\hline f04 & 30 & $3.2007 \mathrm{E}+00$ & $2387 E+00$ & $1469 \mathrm{E}+00$ & \begin{tabular}{|l|}
$2.3978 \mathrm{E}+01$ \\
\end{tabular} & $4745 \mathrm{E}+01$ & $6.0946 \mathrm{E}+00$ & $2.8725 E+00$ & $5.6856 \mathrm{E}+00$ & $1.2431 \mathrm{E}+00$ & $2.8262 \mathrm{E}+01$ & $3.8791 \mathrm{E}+01$ & $1634 \mathrm{E}+0 \mathrm{C}$ \\
\hline f05 & 30 & $.0517 E+02$ & $5058 E+02$ & $9555 \mathrm{E}+01$ & $.0807 E+03$ & $3564 \mathrm{E}+04$ & $1.6310 \mathrm{E}+04$ & & $7246 \mathrm{E}+02$ & & $7.4418 \mathrm{E}+03$ & $3.9130 \mathrm{E}+04$ & $2640 E+0$ \\
\hline f06 & 30 & $2.0000 E+00$ & $7333 E+00$ & $1.8245 \mathrm{E}+00$ & \begin{tabular}{|l|}
$1.7400 \mathrm{E}+02$ \\
\end{tabular} & $9163 \mathrm{E}+02$ & $2.0465 \mathrm{E}+02$ & $.0000 E+00$ & $4.7667 \mathrm{E}+00$ & $15 \mathrm{E}+00$ & $1.3900 \mathrm{E}+02$ & $4.5263 E+02$ & $.8296 \mathrm{E}+02$ \\
\hline f07 & 30 & $2.8562 \mathrm{E}-07$ & $2406 \mathrm{E}-06$ & $1.2872 \mathrm{E}-06$ & \begin{tabular}{|l|}
$7.6867 \mathrm{E}-04$ \\
\end{tabular} & $2135 \mathrm{E}-02$ & $1.4628 \mathrm{E}-02$ & 37E-07 & $1.3833 \mathrm{E}-06$ & \begin{tabular}{|l|}
$1.1343 \mathrm{E}-06$ \\
\end{tabular} & $1.0547 \mathrm{E}-03$ & $1.3451 \mathrm{E}-02$ & $.4276 \mathrm{E}-02$ \\
\hline f08 & 30 & 4.4291E-06 & $3876 \mathrm{E}-05$ & \begin{tabular}{|l|}
$5.7466 \mathrm{E}-06$ \\
\end{tabular} & \begin{tabular}{|l|}
$3.5004 \mathrm{E}-04$ \\
\end{tabular} & $463 E-03$ & $1.2669 \mathrm{E}-03$ & $0828 \mathrm{E}-06$ & $322 E-05$ & \begin{tabular}{|l|}
$7.4610 \mathrm{E}-06$ \\
\end{tabular} & $5.9656 \mathrm{E}-04$ & $8382 \mathrm{E}-03$ & 3377E-03 \\
\hline f09 & 30 & \begin{tabular}{|l|}
$9.4594 \mathrm{E}-01$ \\
\end{tabular} & $9351 E+00$ & $4580 \mathrm{E}-01$ & \begin{tabular}{|l|}
$2.3807 E+01$ \\
\end{tabular} & $3102 \mathrm{E}+01$ & $5.6152 \mathrm{E}+00$ & $1.0236 \mathrm{E}+00$ & $1.9211 \mathrm{E}+00$ & \begin{tabular}{|l|}
$5.7860 \mathrm{E}-01$ \\
\end{tabular} & \begin{tabular}{|l|}
$2.6082 \mathrm{E}+01$ \\
\end{tabular} & $3.4796 \mathrm{E}+01$ & $.4496 \mathrm{E}+0 \mathrm{C}$ \\
\hline $\mathrm{f} 10$ & 30 & 6.3026E-01 & $9236 \mathrm{E}-01$ & $2.3065 \mathrm{E}-01$ & $4.3719 \mathrm{E}+00$ & $7651 E+00$ & $6.6010 \mathrm{E}-01$ & & & & $4.6872 \mathrm{E}+00$ & $5.9257 \mathrm{E}+00$ & $.9267 \mathrm{E}-01$ \\
\hline $\mathrm{f} 11$ & 30 & \begin{tabular}{|l|}
$8.6708 E-01$ \\
\end{tabular} & $0263 E+00$ & $3.4402 \mathrm{E}-02$ & \begin{tabular}{|l|}
$2.1095 \mathrm{E}+00$ \\
\end{tabular} & $4318 \mathrm{E}+00$ & $1.3255 \mathrm{E}+00$ & $5 \mathrm{E}-01$ & $1.0357 \mathrm{E}+00$ & \begin{tabular}{|l|}
$2.7730 \mathrm{E}-02$ \\
\end{tabular} & \begin{tabular}{|l|}
$2.1708 \mathrm{E}+00$ \\
\end{tabular} & $5.0205 E+00$ & $.9755 \mathrm{E}+0 \mathrm{C}$ \\
\hline $\mathrm{f} 12$ & 30 & 5.0934E-03 & 9591E-02 & $3.2559 \mathrm{E}-02$ & \begin{tabular}{|l|}
$1.0493 \mathrm{E}+00$ \\
\end{tabular} & & $3.8957 \mathrm{E}+00$ & & & & $1.4325 \mathrm{E}+00$ & & $.2648 \mathrm{E}+02$ \\
\hline $\mathrm{f} 13$ & 30 & \begin{tabular}{|l|}
$9.3001 \mathrm{E}-02$ \\
\end{tabular} & $.6875 \mathrm{E}-01$ & \begin{tabular}{|l|}
$6.0757 E-02$ \\
\end{tabular} & \begin{tabular}{|l|}
$5.3779 \mathrm{E}+00$ \\
\end{tabular} & $.1883 E+03$ & $1.3051 \mathrm{E}+04$ & \begin{tabular}{|l|}
$8.1548 \mathrm{E}-02$ \\
\end{tabular} & $2.0015 \mathrm{E}-01$ & \begin{tabular}{|l|}
$8.0590 \mathrm{E}-02$ \\
\end{tabular} & $6.9544 \mathrm{E}+00$ & $2.3081 E+03$ & $8.1029 \mathrm{E}+0$ \\
\hline f14 & 2 & $2.1720 \mathrm{E}-11$ & 0558E-08 & $2.1865 \mathrm{E}-07$ & \begin{tabular}{|l|}
$6.4942 \mathrm{E}-10$ \\
\end{tabular} & $4595 E-04$ & 5.4076E-04 & & $8090 \mathrm{E}-10$ & & \begin{tabular}{|l|}
$8.4939 \mathrm{E}-11$ \\
\end{tabular} & $1.0718 \mathrm{E}-07$ & $.3020 \mathrm{E}-07$ \\
\hline $\mathrm{f} 15$ & 4 & 3.9927E-04 & $.0573 \mathrm{E}-04$ & \begin{tabular}{|l|}
$3.2529 \mathrm{E}-04$ \\
\end{tabular} & \begin{tabular}{|l|}
$5.6999 \mathrm{E}-04$ \\
\end{tabular} & \begin{tabular}{|l|}
$1.3729 \mathrm{E}-03$ \\
\end{tabular} & $4.5011 \mathrm{E}-04$ & \begin{tabular}{|l|}
$1.8923 \mathrm{E}-04$ \\
\end{tabular} & $7.0160 \mathrm{E}-04$ & \begin{tabular}{|l|}
$3.1929 \mathrm{E}-04$ \\
\end{tabular} & \begin{tabular}{|l|}
$4.5865 \mathrm{E}-04$ \\
\end{tabular} & $1.3658 \mathrm{E}-03$ & $5.8181 \mathrm{E}-04$ \\
\hline $\mathrm{f} 16$ & 2 & $2.3455 \mathrm{E}-07$ & 1217E-05 & 1.2481E-04 & \begin{tabular}{|l|}
$1.6640 \mathrm{E}-05$ \\
\end{tabular} & $1018 \mathrm{E}-04$ & 4.3907E-04 & $3.5869 \mathrm{E}-10$ & $8485 E-06$ & \begin{tabular}{|l|}
$4.7243 E-06$ \\
\end{tabular} & $5.7770 \mathrm{E}-08$ & $2.7089 \mathrm{E}-05$ & $41 \mathrm{E}-05$ \\
\hline f17 & 2 & 5.6480E-07 & $6466 \mathrm{E}-05$ & 1.6743E-04 & \begin{tabular}{|l|}
$3.6639 E-06$ \\
\end{tabular} & $4432 E-04$ & 3.9477E-04 & & & & $4.4129 E-07$ & $.3364 \mathrm{E}-05$ & $85 \mathrm{E}-05$ \\
\hline $\mathrm{f} 18$ & 2 & $2.7778 \mathrm{E}-05$ & $.5749 \mathrm{E}-03$ & 1.6278E-03 & \begin{tabular}{|l|}
$6.0816 \mathrm{E}-05$ \\
\end{tabular} & $5.8628 \mathrm{E}-03$ & $6.6169 \mathrm{E}-03$ & $1.2784 \mathrm{E}-07$ & $.1736 \mathrm{E}-05$ & $8.7004 \mathrm{E}-05$ & $9.2851 \mathrm{E}-06$ & $2.9315 \mathrm{E}-04$ & $3.7882 \mathrm{E}-04$ \\
\hline f19 & 3 & 7.6177E-06 & $.0374 \mathrm{E}-04$ & \begin{tabular}{|l|}
$3.8211 \mathrm{E}-04$ \\
\end{tabular} & \begin{tabular}{|l|}
$2.5507 E-04$ \\
\end{tabular} & 1.6343E-03 & $1.2888 \mathrm{E}-03$ & & & \begin{tabular}{|l}
$5.9545 \mathrm{E}-05$ \\
\end{tabular} & $1.6327 \mathrm{E}-06$ & $5.2029 \mathrm{E}-04$ & $.9816 \mathrm{E}-04$ \\
\hline $\mathrm{f} 20$ & 6 & $1.8781 \mathrm{E}-03$ & $9158 \mathrm{E}-02$ & \begin{tabular}{|l|}
$6.0706 \mathrm{E}-02$ \\
\end{tabular} & $6659 \mathrm{E}-02$ & $6534 \mathrm{E}-01$ & $.1746 \mathrm{E}-02$ & $3.3727 \mathrm{E}-03$ & $.9192 \mathrm{E}-02$ & \begin{tabular}{|l|}
$5.6884 \mathrm{E}-02$ \\
\end{tabular} & $2.1696 \mathrm{E}-02$ & $1.5974 \mathrm{E}-01$ & $6.5199 \mathrm{E}-02$ \\
\hline $\mathrm{f} 21$ & 1 & $9.8030 \mathrm{E}-08$ & $8723 E-05$ & \begin{tabular}{|l|l|}
$4.2939 E-05$ \\
\end{tabular} & \multirow{3}{*}{\multicolumn{3}{|c|}{$\begin{array}{c}\text { For 1-dimensional problems, SMB-BBO } \\
\text { is not a pplicable; }\end{array}$}} & \begin{tabular}{|c|}
$3.8113 \mathrm{E}-09$ \\
\end{tabular} & $3.3121 E-05$ & \begin{tabular}{|l}
$6.0656 \mathrm{E}-05$ \\
\end{tabular} & \multirow{3}{*}{\multicolumn{3}{|c|}{$\begin{array}{c}\text { For 1-dimensional problems, SSMB-BBC } \\
\text { is not applicable; } \\
\text { (SSMB=SPMB) }\end{array}$}} \\
\hline $\mathrm{f} 22$ & 1 & \begin{tabular}{|l|}
$8.1958 \mathrm{E}-10$ \\
\end{tabular} & $1546 \mathrm{E}-05$ & 5.2185E-05 & & & & \begin{tabular}{|l|}
$2.2393 \mathrm{E}-08$ \\
\end{tabular} & $3.4060 \mathrm{E}-05$ & \begin{tabular}{|l}
$4.6055 \mathrm{E}-05$ \\
\end{tabular} & & & \\
\hline $\mathrm{f} 23$ & 1 & \begin{tabular}{|l|}
$1.7454 \mathrm{E}-08$ \\
\end{tabular} & $7.4624 \mathrm{E}-05$ & $1.8726 \mathrm{E}-04$ & & & & $1.0113 \mathrm{E}-07$ & 3.7714E-05 & $5.3672 E-05$ & & & \\
\hline
\end{tabular}


Table 2.Normalized CPU time for the high-dimensional problems f01-f13

\begin{tabular}{|lllll|}
\hline \multirow{f}{*}{$\#$} & \multicolumn{4}{c}{ BBO Models } \\
\cline { 2 - 5 } & PMB-BBO & SMB-BBO & SPMB-BBO & SSMB-BBO \\
\hline f01 & $1.4804 \mathrm{E}+00$ & $1.0084 \mathrm{E}+00$ & $1.3181 \mathrm{E}+00$ & $\mathbf{1 . 0 0 0 0 E + 0 0}$ \\
f02 & $1.4687 \mathrm{E}+00$ & $1.0086 \mathrm{E}+00$ & $1.3103 \mathrm{E}+00$ & $\mathbf{1 . 0 0 0 0 E + 0 0}$ \\
f03 & $1.1672 \mathrm{E}+00$ & $1.0082 \mathrm{E}+00$ & $1.1104 \mathrm{E}+00$ & $\mathbf{1 . 0 0 0 0 E + 0 0}$ \\
f04 & $1.5018 \mathrm{E}+00$ & $1.0086 \mathrm{E}+00$ & $1.3355 \mathrm{E}+00$ & $\mathbf{1 . 0 0 0 0 E + 0 0}$ \\
f05 & $1.4717 \mathrm{E}+00$ & $1.0074 \mathrm{E}+00$ & $1.3133 \mathrm{E}+00$ & $\mathbf{1 . 0 0 0 0 E + 0 0}$ \\
f06 & $1.4721 \mathrm{E}+00$ & $1.0079 \mathrm{E}+00$ & $1.3113 \mathrm{E}+00$ & $\mathbf{1 . 0 0 0 0 E + 0 0}$ \\
f07 & $1.4089 \mathrm{E}+00$ & $1.0070 \mathrm{E}+00$ & $1.2769 \mathrm{E}+00$ & $\mathbf{1 . 0 0 0 0 E + 0 0}$ \\
f08 & $1.4521 \mathrm{E}+00$ & $1.0074 \mathrm{E}+00$ & $1.2969 \mathrm{E}+00$ & $\mathbf{1 . 0 0 0 0 E + 0 0}$ \\
f09 & $1.4621 \mathrm{E}+00$ & $1.0068 \mathrm{E}+00$ & $1.3041 \mathrm{E}+00$ & $\mathbf{1 . 0 0 0 0 E + 0 0}$ \\
f10 & $1.4299 \mathrm{E}+00$ & $1.0052 \mathrm{E}+00$ & $1.2815 \mathrm{E}+00$ & $\mathbf{1 . 0 0 0 0 E + 0 0}$ \\
f11 & $1.4256 \mathrm{E}+00$ & $1.0070 \mathrm{E}+00$ & $1.2876 \mathrm{E}+00$ & $\mathbf{1 . 0 0 0 0 E + 0 0}$ \\
f12 & $1.3703 \mathrm{E}+00$ & $1.0056 \mathrm{E}+00$ & $1.2437 \mathrm{E}+00$ & $\mathbf{1 . 0 0 0 0 E + 0 0}$ \\
f13 & $1.3878 \mathrm{E}+00$ & $1.0021 \mathrm{E}+00$ & $1.2505 \mathrm{E}+00$ & $\mathbf{1 . 0 0 0 0 E + 0 0}$ \\
\hline Avg CPU Time & $1.4230 \mathrm{E}+00$ & $1.0070 \mathrm{E}+00$ & $1.2800 \mathrm{E}+00$ & $\mathbf{1 . 0 0 0 0 E + 0 0}$ \\
\hline
\end{tabular}

To verify this conclusion, three performance tests have been conducted as shown in Tables 3,4 and 5. Each one of these three tests is focused on one criteria.

Test I is shown in Table 3, and it is used to study the performance of PMB and SPMB algorithms as the problem's dimension decreases. The parameters used for this test are similar to that used in Table 1, except that the generation limit are set as: 1000 for $n=2,4,6 ; 5000$ for $n=10 ; 10,000$ for $n=20$ and 20,000 for $n=30$.

Table 3. Performance Test I - f05 with different dimensions

\begin{tabular}{|c|c|c|c|c|c|c|c|c|}
\hline \multirow{3}{*}{$f \#$} & \multirow{3}{*}{ Name } & \multirow{3}{*}{ Dimensions } & \multicolumn{6}{|c|}{ Biogeography Based Optimization (BBO) } \\
\hline & & & \multicolumn{3}{|c|}{ Partial Migration Based } & \multicolumn{3}{|c|}{ Simplified Partial Migration Based } \\
\hline & & & Best & Mean & StdDev & Best & Mean & StdDev \\
\hline f05a & \multirow{6}{*}{$\begin{array}{l}\text { Generalized } \\
\text { Rosenbrock's } \\
\text { Function }\end{array}$} & 2 & 5.0569E-06 & 3.0404E-04 & $2.9421 \mathrm{E}-04$ & $1.1454 \mathrm{E}-06$ & $4.3368 \mathrm{E}-04$ & $7.0482 \mathrm{E}-04$ \\
\hline f05b & & 4 & $2.6016 \mathrm{E}+00$ & $1.3546 \mathrm{E}+02$ & $1.0058 \mathrm{E}+02$ & $3.8176 \mathrm{E}-01$ & $3.0585 \mathrm{E}+01$ & $3.2854 E+01$ \\
\hline $\mathrm{f05c}$ & & 6 & $4.5589 \mathrm{E}+01$ & $8.1933 E+02$ & \begin{tabular}{|l|l|}
$7.3780 E+02$ \\
\end{tabular} & $4.0158 \mathrm{E}+01$ & $8.3004 \mathrm{E}+02$ & $7.5869 \mathrm{E}+02$ \\
\hline f05d & & 10 & $2.8495 \mathrm{E}+01$ & $2.1690 \mathrm{E}+02$ & $1.8675 \mathrm{E}+02$ & $7.1550 E+01$ & $2.4654 \mathrm{E}+02$ & $1.7535 \mathrm{E}+02$ \\
\hline f05e & & 20 & $8.7400 E+01$ & $3.3766 \mathrm{E}+02$ & $2.4278 E+02$ & $1.3913 \mathrm{E}+02$ & $3.5894 \mathrm{E}+02$ & $4.0126 \mathrm{E}+02$ \\
\hline$\overline{f 05 f}$ & & 30 & $1.0517 \mathrm{E}+02$ & $2.6058 \mathrm{E}+02$ & $7.9555 E+01$ & $1.3597 \mathrm{E}+02$ & $2.7246 \mathrm{E}+02$ & $1.1116 \mathrm{E}+02$ \\
\hline
\end{tabular}

Whereas, Test II shown in Table 4 is used to study the performance of PMB and SPMB algorithms as the number of islands or population size increases for two of low-dimensional problems.

Finally, Test III shown in Table 5 is used to study the performance of PMB and SPMB algorithms under different upper and lower values of the variable bounds (also known as domain, search space, side constraints, etc).

As can be seen from Table 3, the SPMB perform better as the problem dimension decreases. But when the population size is not large, the PMB will performer better even for the low- 
dimensional problems, as shown in Table 4. From Table 5, if the problem search space is large, the PMB wins too.

Table 4. Performance Test II - f15 and f16 with different populations

\begin{tabular}{|c|c|c|c|c|c|c|c|c|}
\hline \multirow{3}{*}{$f \#$} & \multirow{3}{*}{ Name } & \multirow{3}{*}{$\begin{array}{l}\text { Population } \\
\text { Size }\end{array}$} & \multicolumn{6}{|c|}{ Biogeography Based Optimization (BBO) } \\
\hline & & & \multicolumn{3}{|c|}{ Partial Migration Based } & \multicolumn{3}{|c|}{ Simplified Partial Migration Based } \\
\hline & & & Best & Mean & StdDev & Best & Mean & StdDev \\
\hline f15a & \multirow{4}{*}{$\begin{array}{l}\text { Kowalik's } \\
\text { Function }\end{array}$} & 5 & $3.0566 \mathrm{E}-04$ & $1.1017 \mathrm{E}-03$ & $5.6436 \mathrm{E}-04$ & $4.2186 \mathrm{E}-04$ & $1.4561 \mathrm{E}-03$ & 7.5693E-04 \\
\hline $\mathrm{f} 15 \mathrm{~b}$ & & 10 & $5.1379 \mathrm{E}-04$ & $1.2970 \mathrm{E}-03$ & $7.7744 \mathrm{E}-04$ & $2.1192 \mathrm{E}-04$ & $1.0605 \mathrm{E}-03$ & $7.2553 \mathrm{E}-04$ \\
\hline $\mathrm{f} 15 \mathrm{c}$ & & 50 & $3.9927 \mathrm{E}-04$ & $8.0573 \mathrm{E}-04$ & $3.2529 \mathrm{E}-04$ & $1.8923 \mathrm{E}-04$ & $7.0160 \mathrm{E}-04$ & $3.1929 \mathrm{E}-04$ \\
\hline $\mathrm{f} 15 \mathrm{~d}$ & & 200 & $1.9935 \mathrm{E}-04$ & $6.2320 \mathrm{E}-04$ & $2.2726 \mathrm{E}-04$ & $1.4958 \mathrm{E}-04$ & $4.4200 \mathrm{E}-04$ & $1.7749 \mathrm{E}-04$ \\
\hline f16a & \multirow{4}{*}{$\begin{array}{c}\text { Six-Hump Camel- } \\
\text { Back Function }\end{array}$} & 5 & $1.0557 \mathrm{E}-05$ & 6.5798E-04 & $7.0515 \mathrm{E}-04$ & $1.1389 \mathrm{E}-05$ & $8.7138 \mathrm{E}-04$ & $8.0479 \mathrm{E}-04$ \\
\hline f16b & & 10 & $1.1365 \mathrm{E}-07$ & $2.9963 \mathrm{E}-04$ & 4.1067E-04 & $2.4790 \mathrm{E}-06$ & $1.8534 \mathrm{E}-04$ & $2.8880 \mathrm{E}-04$ \\
\hline $\mathrm{f} 16 \mathrm{c}$ & & 50 & $2.3455 \mathrm{E}-07$ & 9.1217E-05 & $1.2481 \mathrm{E}-04$ & $5.7770 \mathrm{E}-08$ & $2.7089 \mathrm{E}-05$ & $3.9141 \mathrm{E}-05$ \\
\hline $\mathrm{f} 16 \mathrm{~d}$ & & 200 & $1.7238 \mathrm{E}-07$ & $2.2757 \mathrm{E}-05$ & $2.7229 \mathrm{E}-05$ & $5.7634 \mathrm{E}-09$ & $5.9924 \mathrm{E}-07$ & $7.5759 \mathrm{E}-07$ \\
\hline
\end{tabular}

Table 5. Performance Test III - f11 with different side constraints

\begin{tabular}{|c|c|c|c|c|c|c|c|c|}
\hline \multirow{3}{*}{$f \#$} & \multirow{3}{*}{ Name } & \multirow{3}{*}{$\begin{array}{c}\text { Side } \\
\text { Constraints }\end{array}$} & \multicolumn{6}{|c|}{ Biogeography Based Optimization (BBO) } \\
\hline & & & \multicolumn{3}{|c|}{ Partial Migration Based } & \multicolumn{3}{|c|}{ Simplified Partial Migration Based } \\
\hline & & & Best & Mean & StdDev & Best & Mean & StdDev \\
\hline f11a & \multirow{3}{*}{$\begin{array}{c}\text { Generalized } \\
\text { Griewank's } \\
\text { Function }\end{array}$} & $\mathrm{Xi} \in[-60,60]$ & $8.6106 \mathrm{E}-02$ & $2.3591 \mathrm{E}-01$ & $8.7067 \mathrm{E}-02$ & $5.3899 \mathrm{E}-02$ & $2.1482 E-01$ & $7.9380 \mathrm{E}-02$ \\
\hline $\mathrm{f} 11 \mathrm{~b}$ & & $x i \in[-600,600]$ & $8.7314 \mathrm{E}-01$ & $1.2508 \mathrm{E}+00$ & $2.3871 \mathrm{E}-01$ & $9.6562 \mathrm{E}-01$ & $1.3044 \mathrm{E}+00$ & $2.2903 \mathrm{E}-01$ \\
\hline f11c & & $x i \in[-6000,6000]$ & $4.9293 \mathrm{E}+00$ & $3.2079 \mathrm{E}+01$ & $2.4023 \mathrm{E}+01$ & $6.0255 \mathrm{E}+00$ & $3.7802 \mathrm{E}+01$ & $2.7235 E+01$ \\
\hline
\end{tabular}

Fig. 3 shows the curves of fitness functions of PMB, SMB, SPMB, and SSMB for theSchwefel's problem 1.2 "f03", Generalized Rosenbrock's function "f05", Generalized Rastrigin's function

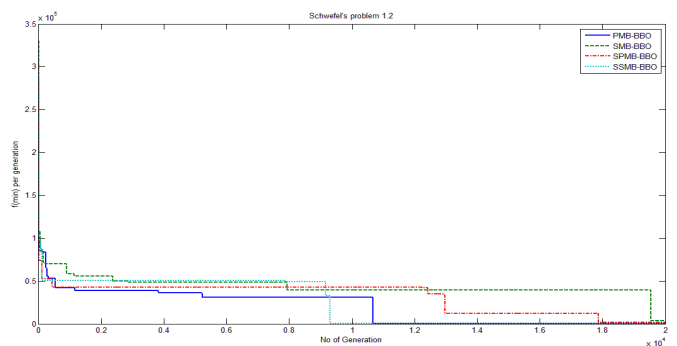

(a)

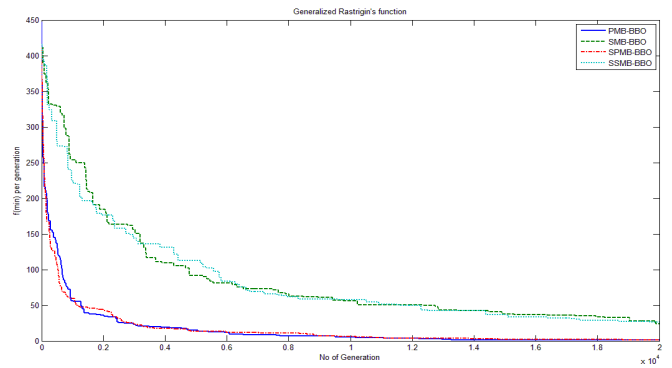

(c)

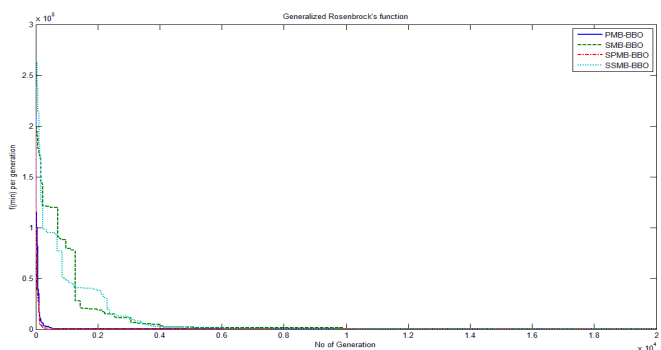

(b)

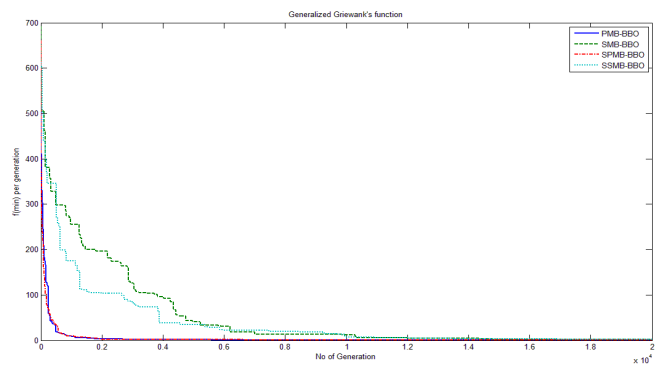

(d)

Figure 3. Curves of fitness functions of PMB, SMB, SPMB, and SSMB for some selected functions.(a) f03, (b) f05, (c) f09, (d) f11 
"f09" and Generalized Griewank's function "f11". For functions f05, f09 and f11, it can be clearly seen that the PMB and SPMB algorithms outperform the SMB and SSMB algorithms, and the gap between the convergences is large. For the function f03, SSMB enters this competition and shows better fitness as compared to SPMB. However, the PMB algorithm is again has the best convergence.

\section{CONCLUSIONS AND SUgGeSTIONS}

The performance of the four original forms of BBO algorithms (PMB, SMB, SPMB and SSMB) have been extensively tested and compared using 23 benchmark functions of different dimensions and complexities, as well as different scenarios have been done for some selected functions. The results show that the PMB, which is the first presented model in 2008, gives the best performance as the complexity, side constraints and/or dimensions of a given problem increases and as the number of islands or population size decreases. However, the PMB is found to be the slowest algorithm which requires around $42.30 \%$ more CPU time than that of the SSMB as shown in Table 2. To compromise between the cost and convergence speed under the above scenarios, SPMB is found to be the best choice as it requires around $28.00 \%$ more CPU time, but its exploration and exploitation will decrease significantly. The performance of the SMB algorithm found to be the worst as compared to the others.

The results obtained in this paper can be used as a foundation and a first step for enhancing any prospective modification on the $\mathrm{BBO}$ algorithm including the existing modifications that are described in literature.

\section{APPENDIX}

This appendix includes a complete list that have been used in this paper. The details of these benchmark functions can be found in [32]. The global minimums of the functions (f08, $\mathrm{f} 14, \mathrm{f} 15, \mathrm{f} 16, \mathrm{f} 17, \mathrm{f} 19, \mathrm{f} 20$, and $\mathrm{f} 21-\mathrm{f} 23)$ are rounded in [32]. In this paper, the correct values are taken instead from $[34,35,36,37,38]$, respectively.

\section{f01: Sphere Model}

$$
f(x)=\sum_{i=1}^{n} x_{i}^{2}
$$

- $\quad-100 \leq x_{i} \leq 100, \quad i=1,2, \ldots, n$

- $f_{\min }\left(X^{*}\right)=0, x_{i}^{*}=0$

f02: Schwefel's Problem 2.22

$$
f(x)=\sum_{i=1}^{n}\left|x_{i}\right|+\prod_{i=1}^{n}\left|x_{i}\right|
$$

- $-10 \leq x_{i} \leq 10, \quad i=1,2, \ldots, n$

- $f_{\min }\left(X^{*}\right)=0, x_{i}^{*}=0$ 
f03: Schwefel's Problem 1.2

$$
f(x)=\sum_{i=1}^{n}\left(\sum_{j=1}^{i} x_{j}\right)^{2}
$$

- $-100 \leq x_{i} \leq 100, \quad i=1,2, \ldots, n$

- $f_{\text {min }}\left(X^{*}\right)=0, \quad x_{i}^{*}=0$

f04: Schwefel's Problem 2.21

$$
f(x)=\max _{i}\left\{\left|x_{i}\right|, 1 \leq i \leq n\right\}
$$

- $\quad-100 \leq x_{i} \leq 100, \quad i=1,2, \ldots, n$

- $f_{\text {min }}\left(X^{*}\right)=0, x_{i}^{*}=0$

f05: Generalized Rosenbrock's Function

$$
f(x)=\sum_{i=1}^{n-1}\left[100\left(x_{i+1}-x_{i}^{2}\right)^{2}+\left(x_{i}-1\right)^{2}\right]
$$

- $\quad-30 \leq x_{i} \leq 30, \quad i=1,2, \ldots, n$

- $f_{\min }\left(X^{*}\right)=0, \quad x_{i}^{*}=1$

f06: Step Function

$$
f(x)=\sum_{i=1}^{n}\left(\left\lfloor x_{i}+0.5\right\rfloor\right)^{2}
$$

- $\quad-100 \leq x_{i} \leq 100, \quad i=1,2, \ldots, n$

- $f_{\text {min }}\left(X^{*}\right)=0, x_{i}^{*}=0$

f07: Quartic Function

$$
f(x)=\sum_{i=1}^{n} i x_{i}^{4}
$$

- $\quad-1.28 \leq x_{i} \leq 1.28, \quad i=1,2, \ldots, n$

- $f_{\min }\left(X^{*}\right)=0, x_{i}^{*}=0$

f08: Generalized Schwefel's Problem 2.26

$$
f(x)=-\sum_{i=1}^{n}\left[x_{i} \sin \left(\sqrt{\left|x_{i}\right|}\right)\right]
$$

- $-500 \leq x_{i} \leq 500, \quad i=1,2, \ldots, n$,

- $f_{\min }\left(X^{*}\right)=-418.982887272433799807913601398 n, x_{i}^{*}=420.968748$

f09: Generalized Rastrigin's Function

$$
f(x)=\sum_{i=1}^{n}\left[x_{i}^{2}-10 \cos \left(2 \pi x_{i}\right)+10\right]
$$


- $\quad-5.12 \leq x_{i} \leq 5.12, \quad i=1,2, \ldots, n$

- $f_{\min }\left(X^{*}\right)=0, \quad x_{i}^{*}=0$

f10: Ackley's Function

$$
f(x)=-20 e^{\left(-0.2 \sqrt{\frac{1}{n} \sum_{i=1}^{n} x_{i}^{2}}\right)}-e^{\left(\frac{1}{n} \sum_{i=1}^{n} \cos \left(2 \pi x_{i}\right)\right)}+20+e^{(1)}
$$

- $-32 \leq x_{i} \leq 32, \quad i=1,2, \ldots, n$

- $f_{\min }\left(X^{*}\right)=0, x_{i}^{*}=0$

f11: Generalized Griewank's Function

$$
f(x)=\frac{1}{4000} \sum_{i=1}^{n} x_{i}^{2}-\prod_{i=1}^{n} \cos \left(\frac{x_{i}}{\sqrt{i}}\right)+1
$$

- $-600 \leq x_{i} \leq 600, \quad i=1,2, \ldots, n$

- $f_{\min }\left(X^{*}\right)=0, x_{i}^{*}=0$

\section{f12: Generalized Penalized No.1 Function}

$$
f(x)=\frac{\pi}{n}\left\{10 \sin ^{2}\left(\pi y_{1}\right)+\sum_{i=1}^{n-1}\left(y_{i}-1\right)^{2}\left[1+10 \sin ^{2}\left(\pi y_{i+1}\right)\right]+\left(y_{n}-1\right)^{2}\right\}+\sum_{i=1}^{n} u\left(x_{i}, a, k, m\right)
$$

where

$$
y_{i}=1+\frac{1}{4}\left(x_{i}+1\right), \quad u\left(x_{i}, a, k, m\right)=\left\{\begin{aligned}
k\left(x_{i}-a\right)^{m} x_{i} & >a \\
0 & -a \leq x_{i} \leq a \\
k\left(-x_{i}-a\right)^{m} x_{i} & <-a
\end{aligned}\right.
$$

- $a=10, k=100 \quad \& \quad m=4$

- $-50 \leq x_{i} \leq 50, \quad i=1,2, \ldots, n$

- $f_{\text {min }}\left(X^{*}\right)=0, x_{i}^{*}=1$

\section{f13: Generalized Penalized No.2 Function}

$$
\begin{gathered}
f(x)=0.1\left\{\sin ^{2}\left(3 \pi x_{1}\right)+\sum_{i=1}^{n-1}\left(x_{i}-1\right)^{2}\left[1+\sin ^{2}\left(3 \pi x_{i+1}\right)\right]+\left(x_{n}-1\right)^{2}\left[1+\sin ^{2}\left(2 \pi x_{n}\right)\right]\right\} \\
+\sum_{i=1}^{n} u\left(x_{i}, a, k, m\right)
\end{gathered}
$$

where

$$
u\left(x_{i}, a, k, m\right)=\left\{\begin{aligned}
k\left(x_{i}-a\right)^{m} x_{i} & >a \\
0 & -a \leq x_{i} \leq a \\
k\left(-x_{i}-a\right)^{m} x_{i} & <-a
\end{aligned}\right.
$$

- $a=5, k=100 \quad \& \quad m=4$

- $-50 \leq x_{i} \leq 50, \quad i=1,2, \ldots, n$

- $f_{\min }\left(X^{*}\right)=0, x_{i}^{*}=1$ 
f14: Shekel's Foxholes Function

$$
f(x)=\left[\frac{1}{500}+\sum_{j=1}^{25} \frac{1}{j+\sum_{i=1}^{2}\left(x_{i}-a_{i, j}\right)^{6}}\right]^{-1}
$$

where

$$
\begin{aligned}
a_{i, j} & =\left[\begin{array}{rrrrrrrrrc}
-32 & -16 & 0 & 16 & 32 & -32 & \ldots & 0 & 16 & 32 \\
-32 & -32 & -32 & -32 & -32 & -16 & \ldots & 32 & 32 & 32
\end{array}\right] \\
-\quad-65.536 & \leq x_{i} \leq 65.536, \quad i=1,2 \\
-f_{\min }\left(X^{*}\right) & \approx 0.998003837794449325873406851315, \quad x_{i}^{*} \approx-31.97833
\end{aligned}
$$

\section{f15: Kowalik's Function}

$$
f(x)=\sum_{j=1}^{11}\left[a_{j}-\frac{x_{1}\left(b_{j}^{2}+b_{j} x_{2}\right)}{b_{j}^{2}+b_{j} x_{3}+x_{4}}\right]^{2}
$$

- $-5 \leq x_{i} \leq 5, \quad i=1,2,3,4$

- $f_{\text {min }}\left(X^{*}\right) \approx 0.0003074859878056042168404344971009$,

- $x_{i}^{*} \approx\left\{\begin{array}{l}0.192833452744335301314942585123 \\ 0.190836242203235800915303666443 \\ 0.123117296029247410738689372920 \\ 0.135765991801668826273045769995\end{array}\right\}$

Table 6. Data for Kowalik's Function

\begin{tabular}{|l|c|l|}
\hline$j$ & $a_{j}$ & $b_{j}^{-1}$ \\
\hline 1 & 0.1957 & 0.25 \\
2 & 0.1947 & 0.5 \\
3 & 0.1735 & 1 \\
4 & 0.1600 & 2 \\
5 & 0.0844 & 4 \\
6 & 0.0627 & 6 \\
7 & 0.0456 & 8 \\
8 & 0.0342 & 10 \\
9 & 0.0323 & 12 \\
10 & 0.0235 & 14 \\
11 & 0.0246 & 16 \\
\hline
\end{tabular}

\section{f16: Six-Hump Camel-Back Function}

$$
f(x)=4 x_{1}^{2}-2.1 x_{1}^{4}+\frac{1}{3} x_{1}^{6}+x_{1} x_{2}-4 x_{2}^{2}+4 x_{2}^{4}
$$

- $-5 \leq x_{i} \leq 5, \quad i=1,2$

- $f_{\min }\left(X^{*}\right)=-1.031628453489877$ "It has four global minimum",

- $x_{i}^{*}=( \pm 0.08984201368301331, \pm 0.7126564032704135)$

\section{f17: Branin RCOS Function}

$$
f(x)=\left(x_{2}-\frac{5.1}{4 \pi^{2}}\right) x_{1}^{2}+\left(\frac{5}{\pi} x_{1}-6\right)^{2}+10\left(1-\frac{1}{8 \pi}\right) \cos \left(x_{1}\right)+10
$$


- $-5 \leq x_{1} \leq 10, \quad 0 \leq x_{2} \leq 15$

- $f_{\min }\left(X^{*}\right)=0.39788735772973816$ "It has three global minimum",

- $x_{i}^{*}=(-\pi, 12.275),(\pi, 2.275),(9.42478,2.475)$

\section{f18: Goldstein-Price Function}

$$
f(x)=f_{1}(x) f_{2}(x)
$$

where

$$
\begin{aligned}
f_{1}(x) & =1+\left(x_{1}+x_{2}+1\right)^{2}\left(19-14 x_{1}+3 x_{1}^{2}-14 x_{2}+6 x_{1} x_{2}+3 x_{2}^{2}\right) \\
f_{2}(x) & =30+\left(2 x_{1}-3 x_{2}\right)^{2}\left(18-32 x_{1}+12 x_{1}^{2}+48 x_{2}-36 x_{1} x_{2}+27 x_{2}^{2}\right) \\
-\quad-2 \leq x_{i} & \leq 2, \quad i=1,2 \\
-\quad & f_{\min }\left(X^{*}\right)=3, \quad x_{i}^{*}=(0,-1)
\end{aligned}
$$

\section{f19,20: Hartman's Family}

$$
f(x)=-\sum_{i=1}^{m} c_{i} \exp \left[-\sum_{j=1}^{n} a_{i, j}\left(x_{j}-p_{i, j}\right)^{2}\right]
$$

- $m=4, n=3,6$ for $f 19$ and $f 20$, respectively

- $0 \leq x_{j} \leq 1, \quad j=1,2, \ldots, n$

- $f 19: f_{\min }\left(X^{*}\right)=-3.86278214782076, \quad x_{i}^{*}=\left\{\begin{array}{c}0.1, \\ 0.55592003, \\ 0.85218259\end{array}\right\}$

- $f 20: f_{\min }\left(X^{*}\right)=-3.32236801141551, \quad x_{i}^{*}=\left\{\begin{array}{l}0.20168952, \\ 0.15001069, \\ 0.47687398, \\ 0.27533243, \\ 0.31165162, \\ 0.65730054\end{array}\right\}$

Table 7: Data for Hartman's Function 1

\begin{tabular}{|l|l|l|l|l|l|l|l|}
\hline$i$ & \multicolumn{2}{|c|}{$\begin{array}{l}a_{i, j}, j \\
=1,2,3\end{array}$} & $c_{i}$ & \multicolumn{3}{c|}{$p_{i, j}, j=1,2,3$} \\
\hline 1 & 3 & 10 & 30 & 1 & 0.3689 & 0.1170 & 0.2673 \\
\hline 2 & 0.1 & 10 & 35 & 1.2 & 0.4699 & 0.4387 & 0.7470 \\
\hline 3 & 3 & 10 & 30 & 3 & 0.1091 & 0.8732 & 0.5547 \\
\hline 4 & 0.1 & 10 & 35 & 3.2 & 0.038150 & 0.5743 & 0.8828 \\
\hline
\end{tabular}

Table 8: Data for Hartman's Function 2

\begin{tabular}{|c|l|l|l|l|l|l|l|l|l|l|l|l|}
\hline$i$ & $c_{i}$ & \multicolumn{5}{|c|}{$a_{i, j}, j=1,2, \ldots, 6$} & \multicolumn{5}{c|}{$p_{i, j}, j=1,2, \ldots, 6$} \\
\hline 1 & 1 & 10 & 3 & 17 & 1.7 & 8 & 0.1312 & 0.1696 & 0.5569 & 0.0124 & 0.8283 & 0.5886 \\
\hline 2 & 1.2 & 0.05 & 10 & 17 & 8 & 14 & 0.2329 & 0.4135 & 0.8307 & 0.3736 & 0.1004 & 0.9991 \\
\hline 3 & 3 & 3 & 3.5 & 1.7 & 17 & 8 & 0.2348 & 0.1415 & 0.3522 & 0.2883 & 0.3047 & 0.6650 \\
\hline 4 & 3.2 & 17 & 8 & 0.05 & 0.1 & 14 & 0.4047 & 0.8828 & 0.8732 & 0.5743 & 0.1091 & 0.0381 \\
\hline
\end{tabular}


f21,22,23: Shekel's Family

$$
f(x)=-\sum_{i=1}^{n}\left[\left(x-a_{i}\right)\left(x-a_{i}\right)^{T}+c_{i}\right]
$$

- $n=5,7$ and 10 for $f 21, f 22$ and $f 23$, respectively

- $0 \leq x \leq 10, \quad i=1,2, \ldots, n$

- $f 21: f_{\min }\left(x^{*}\right)=-10.153198755084881776356839400251$,

$$
x^{*}=4.000085212027619539925233402760
$$

- $f 22: f_{\min }\left(x^{*}\right)=-10.402822044707775329070518200751$,

$$
x^{*}=4.000089532152739968028886505640
$$

- $f 23: f_{\min }\left(x^{*}\right)=-10.536290299294717105427357601002$,

\begin{tabular}{|c|c|c|c|c|c|}
\hline$i$ & \multicolumn{4}{|c|}{$a_{i j}, j=1,2,3,4$} & $c_{i}$ \\
\hline 1 & 4 & 4 & 4 & 4 & 0.1 \\
\hline 2 & 1 & 1 & 1 & 1 & 0.2 \\
\hline 3 & 8 & 8 & 8 & 8 & 0.2 \\
\hline 4 & 6 & 6 & 6 & 6 & 0.4 \\
\hline 5 & 3 & 7 & 3 & 7 & 0.4 \\
\hline 6 & 2 & 9 & 2 & 9 & 0.6 \\
\hline 7 & 5 & 5 & 3 & 3 & 0.3 \\
\hline 8 & 8 & 1 & 8 & 1 & 0.7 \\
\hline 9 & 6 & 2 & 6 & 2 & 0.5 \\
\hline 10 & 7 & 3.6 & 7 & 3.6 & 0.5 \\
\hline
\end{tabular}

$$
x^{*}=4.0001281610100453290705182007510
$$

Table 9: Data for Shekel Functions $f 21, f 22, f 23$

\section{REFERENCES}

[1] Dan. Simon, "Biogeography-based optimization," IEEE Trans. On Evolutionary Computation, vol. 12, no. 6, pp. 702-713, Dec. 2008.

[2] Robert H. MacArthur and Edward O. Wilson, "An Equilibrium Theory of Insular Zoogeography," Journal of Evolution, vol. 17, no. 4, pp. 373-387, Dec. 1963.

[3] Robert H. MacArthur and Edward O. Wilson, The Theory of Island Biogeography. Princeton, New Jersey: Princeton University Press, 1967.

[4] Mark V. Lomolino, Brett R. Riddle and James H. Brown, Biogeography, 3rd ed. Sunderland, Massachusetts: Sinauer Associates Inc., 2009.

[5] R. L. Jones, Biogeography: Structure, Process, Pattern and Change within the Biosphere. Amersham, Bucks, England: Hulton Educational Publications, 1980.

[6] C. Barry Cox and Peter D. Moore, Biogeography: An Ecological and Evolutionary Approach, 5th ed. Oxford, UK: Blackwell Scientific Publications, 1993.

[7] R. J. Lincoln, G. A. Boxshall and P. F. Clark, A dictionary of Ecology, Evolution and Systematics. Cambridge, UK: Cambride University Press, 1982.

[8] PaulamiMaiti and Prabodh K. Maiti, Biodiversity: Perception, Peril and Preservation. Prentice-Hall of India, 2011.

[9] William A. Nierenberg, Encyclopedia of Environmental Biology, vol. 2. San Diego, California: Academic Press Inc., 1995.

[10] Michael Shermer, In Darwin's Shadow: The Life and Science of Alfred Russel Wallace. New York: Oxford University Press, 2002.

[11] Frank J. Sulloway, "Darwin and His Finches: The evolution of a Legend," Journal of the History of Biology, vol. 15, no. 1, pp. 1-53, March 1982.

[12] Ray Desmond, Sir Joseph Dalton Hooker: Traveller and Plant Collector. Woodbridge, Suffolk: UK: Antique Collectors Club, 2007. 
[13] Jonathan B. Losos and Robert E. Ricklefs, The Theory of Island Biogeography Revisited. Princeton, New Jersey: Princeton University Press, 2010.

[14] Alan A. Myers and Paul S. Giller, Analytical Biogeography: An Integrated Approach to the Study of Animal and Plant Distributions. London, UK: Chapman and Hall, 1990.

[15] Glen M. MacDonald, Biogeography: Space, Time and Life. New York: John Wiley \& Sons Inc., 2003.

[16] Martin L. Cody, Plants on Islands: Diversity and Dynamics on a Continental Archipelago. Berkeley and Los Angeles, California: University of California Press, 2006.

[17] Robert H. MacArthur and Joseph H. Connell, The Biogeography of Populations. New York: John Wiley \& Sons Inc., 1966.

[18] Robert H. MacArthur, Geographical Ecology: Patterns in the Distribution of Species. New York: Harper \& Row Publishers Inc., 1972.

[19] Yu. M. Svirezhev and D. O. Logofet, Stability of Biological Communities. Moscow, Soviet Union: Mir Publishers, 1983.

[20] A. Bhattacharya and P. K. Chattopadhyay, "Biogeography-Based Optimization and its application to nonconvex Economic Emission Load Dispatch problems," 8th International Conference on Advances in Power System Control, Operation and Management (APSCOM 2009), pp. 1-6, Nov. 2009.

[21] V. K. Panchal, S. Goel and M. Bhatnagar, "Biogeography based land cover feature extraction,". World Congress on Nature \& Biologically Inspired Computing. NaBIC 2009, pp. 1588-1591, Dec. 2009.

[22] Z. Mohammed and J. Talaq, "Unit commitment by biogeography based optimization method," 16th IEEE Mediterranean Electrotechnical Conference (MELECON), pp. 551-554, March 2012.

[23] M. Ergezer, Dan. Simon and Dawei Du, "Oppositional biogeography-based optimization," IEEE International Conference on Systems, Man and Cybernetics. pp. 1009-1014, Oct. 2009.

[24] Haiping Ma, Suhong Ni and Man Sun, "Equilibrium species counts and migration model tradeoffs for biogeography-based optimization," Proceedings of the 48th IEEE Conference on Decision and Control, held jointly with the 28th Chinese Control Conference. CDC/CCC 2009. pp. 3306-3310, Dec. 2009.

[25] H. Ma, "An analysis of the equilibrium of migration models for biogeography-based optimization," Information Sciences, vol. 180, no. 18, pp. 3444-3464, 15 Sept. 2010.

[26] S. S. Pattnaik, M. R. Lohokare and S. Devi, "Enhanced Biogeography-Based Optimization using modified clear duplicate operator," Second World Congress on Nature and Biologically Inspired Computing (NaBIC), pp. 715-720, Dec. 2010.

[27] Haiping Ma and Dan. Simon, "Blended biogeography-based optimization for constrained optimization," Engineering Applications of Artificial Intelligence, vol. 24, no. 3, pp. 517-525, Apr. 2011.

[28] Dan. Simon. (2009, Feb.). A Probabilistic Analysis of a Simplified Biogeography-Based Optimization Algorithm. Cleveland State University. Cleveland, Ohio. Available: http://academic.csuohio.edu/simond/bbo/simplified/bbosimplified.pdf

[29] Haiping Ma and Dan. Simon, "Analysis of migration models of biogeography-based optimization using Markov theory," Engineering Applications of Artificial Intelligence, vol. 24, no. 6, pp. 1052 1060, Sept. 2011.

[30] Dan. Simon, M. Ergezer and Dawei Du, "Population distributions in biogeography-based optimization algorithms with elitism," IEEE International Conference on Systems, Man and Cybernetics, pp. 991996, Oct. 2009.

[31] Dario Floreano and Claudio Mattiussi, Bio-Inspired Artificial Intelligence: Theories, Methods, and Technologies. Cambridge, Massachusetts: The MIT Press, 2008.

[32] Xin Yao, Yong Liu and Guangming Lin, "Evolutionary Programming Made faster," IEEE Trans. on Evolutionary Computation, vol. 3, no. 2, pp. 82-102, Jul. 1999.

[33] Wenying Gong, ZhihuaCai and Charles X. Ling, "DE/BBO: A hybrid differential evolution with biogeography-based optimization for global numerical optimization," Soft Computing, vol. 15, no. 4, pp. 645-665, Apr. 2011.

[34] Lappeenranta University of Technology, "The function testbed," [online] May. 2007, http://www.it.lut.fi/ip/evo/functions/functions.html(Acc-essed: 10 April 2013).

[35] Chien-Wen Chao, Shu-CherngFand and Ching-Jong Liao, "A Tropical cyclone-based method for global optimization," Journal of Industrial and Management Optimization, Vol. 8, no. 1, Feb. 2012. 
[36] M. Montaz Ali, CharoenchaiKhompatraporn and Zelda B. Zabinsky, "A Numerical Evaluation of Several Stochastic Algorithms on Selected Continuous Global Optimization Test Problems" Journal of Global Optimization, vol. 31, no. 4, pp. 635-672, Apr. 2005.

[37] Andrea Gavana, "Test Functions Index," [online] Feb. 2013, http://infinity77.net/global_optimization/test_functions.html (Accessed: 01 April 2013).

[38] Muhammad Aria, "Educational Simulator for Teaching of Particle Swarm Optimization in LabVIEW," TELEKONTRAN, vol. 1, no. 1, Jan. 2013.

\section{Authors}

Ali Ridha Alroomi received the B.Sc. degree in Process Instrumentation and Control Engineering from University of Bahrain, Bahrain, in 2006. In the period between 20092013, he covered the electrical courses of the B.Sc. program in Electrical Engineering, and followed by M.Sc. degree from the same university. After B.Sc. graduation, he was selected to be as a project engineer in Moore Control \& Engineering till the mid of 2007, when he joined Yokogawa Middle East as a DCS subsystem and graphics engineer. From 2008 to 2012, he worked in Aluminum Bahrainas an instrumentation and control engineer in its power plants, generation and auxiliary C\&I maintenance. He is currently working as a researcher in the field of electrical power systems and evolutionary computation.

Fadhel Abbas Al-Basri received the B.Sc. and M.Sc. degrees in Electrical Engineeringfrom University ofBahrain, Bahrain, and Ph.D. degree in the same field from University of Western Ontario, Canada,in 1992, 1997 and 2007, respectively. He worked in Ministry of Electricity and Water, Bahrain, as an electrical engineer from 1993 to 1994. In 1994, he joined the University ofBahrain as teaching and research assistant and currently an assistant professor in the department of electrical engineering. His research interest is power systems protection, power systems analysis andFACTS-devices.

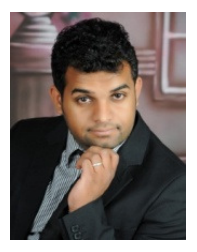

Jawad Hasan Talaq received B.Sc. degree from University of Technology, Baghdad, Iraq (1981), M.Sc. degree from University of Strathclyde, Glasgow, UK (1987), and Ph.D. degree from Technical University of Nova Scotia, Halifax, Canada (1993); all in electrical engineering. He worked in Ministry of Electricity and Water, Bahrain, as a graduate engineer in Riffa power plant from 1981 to 1985 , and as a shift charge engineer from 1985 to 1989 , till moving from the industrial field to the academic field. He is now an associate professor in the department of electrical engineering, University of Bahrain.

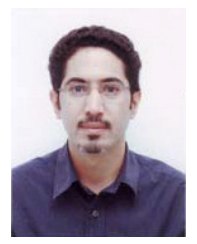
His teaching covers power systems operation and control, power systems dynamics, and advanced power systems analysis; where his research topics include power systems operation, control and dynamics, and applied soft computing. 